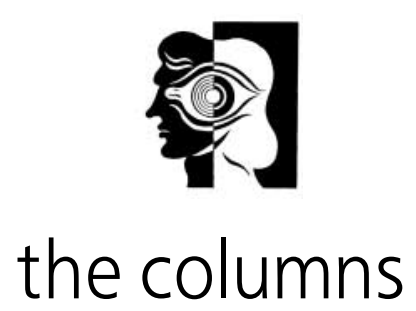

correspondence

\section{Surely you take complementary and alternative medicines?}

The article 'Surely you take complementary and alternative medicines?'

(Psychiatric Bulletin, February 2004, 28, 36-39) has been read with much interest. The content of the article is highly relevant to developing countries as many patients seek complementary and alternative medicines for a variety of illnesses, particularly for long-standing problems including psychiatric disorders. Many patients and their relatives seem to go for alternative therapies in addition to Western medicine. For instance, a study done with regard to puerperal mental disorders in Sri Lanka demonstrated that up to $80 \%$ of patients were seeking alternative or complementary medicines in addition to conventional ones (further details available from the author upon request).

It is noteworthy that many herbal preparations seem to contain cannabis, and sometimes alcohol, in addition to the other chemicals. Certainly these substances can precipitate psychiatric disorders or exacerbate existing symptoms. The other important issue, as correctly mentioned in the article, is their potential dangerous drug interactions with prescribed medicines.

Many patients appear to have a good rapport with traditional healers and people who practise complementary and alternative medicine in our countries. Hence, those of us who practise Western medicine must be aware of this important issue and deal with it tactfully and effectively. Undergraduate and post-graduate medical curricula must be strengthened with regard to this in order to improve the awareness among doctors.

\section{K. A. L. A. Kuruppuarachchi}

Professor of Psychiatry, University of Kelaniya, Ragama, Sri Lanka

\section{Not only examiners!}

Dr Chaudhray (Psychiatric Bulletin, February 2004, 28, 67) is not alone in having a professional leave treated as study leave by his employer. However, the letter raises a far broader issue than membership examinations.

My employers treat all professional leave as study leave. Thus examining, sitting on appointment panels, attending College committees, giving time to advise the Scottish Executive Health Department and many other activities are considered study. Meanwhile, it is self-evident that such activities do little for my continuing professional development (CPD). As a consequence, neither time nor funding are available for genuine study leave (and my PDP does not include 'a leisurely walk in Hyde Park' among its peer group approved objectives!). This position sits paradoxically with NHS clinical governance, College, appraisal, revalidation and employment requirements to maintain good practice through CPD. In the families of schizophrenia sufferers, we try to address such double binds because of their negative prognostic implications.

As a College, can we intervene while the NHS prognosis might be amenable to improvement?

Nicholas Walker Consultant Psychiatrist, Ravenscraig Hospital, Inverich Road, Greenock PA16 9HA.

E-mail: Nick.Walker@renver-pct.scot.nhs.uk 